\title{
Organik Çay Tarımında Budama Yaşı ve Diurnal Varyabilitenin Çay (Camellia sinensis (L.) O. Kuntz) Yapraklarının Antioksidan Aktivitesi Üzerine Etkisi ${ }^{\#}$
}

\author{
Yusuf Şavşatlı*, Aysel Özcan, Muhammed İkbal Çatal, Emine Yurteri, Fatih Seyis \\ Recep Tayyip Erdoğan Üniversitesi, Ziraat ve Doğa Bilimleri Fakültesi, Tarla Bitkileri Bölümü, 53300 Pazar/Rize, Türkiye
}

\section{A K A L E B İ L G İ S İ}

\#27-29 Eylül 2017'de Bayburt / Türkiye'de düzenlenen ' 1 st International Organic Agriculture and Biodiversity' kongresinde özet olarak sunulmuştur.

\section{Araştırma Makalesi}

Geliş 11 Eylül 2017

Kabul 07 Ocak 2018

Anahtar Kelimeler:

Çay

Budama

Diurnal varyabilite

Antioksidan

Kuru madde

*Sorumlu Yazar:

E-mail: yusuf.savsatli@erdogan.edu.tr

\section{Ö Z E T}

Bu çalışma, 2016 yılında Rize İl'inde organik çay tarımı yapılan bir araziden toplanan taze yaprak örnekleri üzerinden yürütülmüsşür. Araştırmada, budama yaşının (en son budamadan sonraki 1 . y1l, 3. y1l ve 5. y1l) ve diurnal varyabilitenin sürgün dönemlerine bağlı olarak çay yapraklarında antioksidan aktivite ve kuru madde oranı üzerindeki etkisi belirlenmeye çalışılmıştır. Budama yaşı dikkate alındığında, 1. sürgün döneminde en yüksek antioksidan aktivite $4991,1 \mu \mathrm{mol} \mathrm{FeSO}_{4} / \mathrm{g} \mathrm{km}$ ile 5 . budama yaşında olan bitkilerden elde edilmiştir. Aynı özellik bakımından, budama yaşının 2. sürgün döneminde antioksidan aktivitesi üzerindeki etkisi önemsiz çıkarken; 3. sürgün döneminde en yüksek antioksidan aktivite $7229,2 \mu \mathrm{mol} \mathrm{FeSO}_{4} / \mathrm{g} \mathrm{km}$ ile 1. budama yaşında tespit edilmiştir. Genel ortalama olarak, gün içi toplama zamanı dikkate alındığında sabah saatinde $(07 . \underline{00})$ ve öğle saatinde $(12 . \underline{00})$ toplanan yapraklarda antioksidan aktivitesi birbirine çok yakın değerlerden oluşurken; akşam saatinde (17. .00$)$ toplanan yapraklar daha yüksek değerlere sahip olmuştur. 1,3 ve 5 . budama yaşında elde edilen kuru madde oranları sırasıyla $\% 23,45, \% 25,23$ ve $\% 25,45$ olarak gerçekleşmiştir. Sürgün dönemleri dikkate alındığında, en düşük kuru madde oran $1 \% 20,17$ ile 1 . sürgün döneminde; en yüksek kuru madde oranı ise $\% 28,8$ ile 2 . sürgün döneminde gerçekleşmiş; öğle saatinde toplanan yapraklardan yüksek değerler elde edilmiştir.

Turkish Journal of Agriculture - Food Science and Technology, 6(2): 163-168, 2018

The Effect of Pruning Age and Diurnal Variability on the Antioxidant Activity of Tea (Camellia sinensis (L.) O. Kuntz) Leaves in Organic Tea Farming

\section{A R T I C L E I N F O}

\section{Research Article}

Received 11 September 2017

Accepted 07 January 2018

Keywords:

Tea

Pruning

Diurnal variability

Antioxidant

Dry matter

\begin{tabular}{l}
\hline Corresponding Author: \\
\hline E-mail: yusuf.savsatli@erdogan.edu.tr
\end{tabular}

A B S T R A C T

This study was carried out in Rize province in 2016, on fresh leaf samples collected from an organic tea plantation. In this study, the aim was to determine the effect of pruning age (1st year, 3rd year and 5th year following the last pruning) and diurnal variability on antioxidant activity and dry matter rate in tea leaves depending on shoot periods. When the pruning age was considered, the highest antioxidant activity was obtained from the plants which were in 5th pruning age in the 1 st shoot period with $4991,1 \mu \mathrm{mol} \mathrm{FeSO} 4 / \mathrm{g}$ $\mathrm{dw}$. In terms of the same trait, the effect of pruning age on antioxidant activity during the $2^{\text {nd }}$ shoot period was insignificant, while the highest antioxidant activity in the third shoot period was obtained from $1^{\text {st }}$ pruning age with $7229.2 \mu \mathrm{mol} \mathrm{FeSO} 4 / \mathrm{g}$ dw. As a general average, considering intraday collecting time, antioxidant activity in leaves collected in morning $(07 . \underline{00})$ and at noon $(12 . \underline{00})$ was very close to each other, while the collected leaves in the evening (17.무) had higher values. The dry matter rates obtained from the 1 st, $3^{\text {rd }}$ and $5^{\text {th }}$ pruning ages were $23.45 \%, 25.23 \%$ and $25.45 \%$ respectively. When the shoot period was considered, the lowest dry matter rate was $20.17 \%$ in the first shoot period and the highest dry matter rate was $28.8 \%$ in the $2^{\text {nd }}$ shoot period and high values were obtained from the leaves collected at noon. 


\section{Giriş}

Türkiye'nin yoğun olarak tüketilen milli içeceği olan çay Camellia sinensis (O) Kuntz türünün taze yapraklarından elde edilmektedir. Tıbbi etkileri yaklaşık 5000 y1llık bir geçmişe dayanan çay yüzyıllar önce ilaç olarak değerlendirilirken, daha sonra içecek olarak önem kazanmış ve şimdi ise sanayiye hammadde sağlanmasında ciddi bir potansiyele sahip değerli bir bitki haline gelmiştir (Sharangi, 2009).

İşleme yöntemlerine bağlı olarak siyah çay, yeşil çay, oolong çay ve beyaz çay gibi çeşitli çay tipleri bulunmakta olup, Dünya'da olduğu gibi Türkiye'de de en fazla tüketilen siyah çaydır (FAO, 2015; ÇAYKUR, 2016). Yeşil çay ise tüketim sıralamasında siyah çaydan sonra gelmektedir. Farklı ticari çay örnekleri üzerinde yürütülen bir çalışmada; yeşil çayın, oolong çay ve siyah çaya göre daha yüksek kateşin içeriğine sahip olduğu ifade edilmekte; bunun nedeni ise imalat sirasındaki fermentasyon sürecinin kateşin seviyesini önemli derecede düşürmesine bağlanmaktadır (Cabrera ve ark., 2003). Yeşil çayın başlıca kimyasal bileşenleri arasında polifenoller, kafein ve amino asitlerin yer aldığı ve birçok faydalı etkileri olan bileşiklerin antioksidan özelliklere sahip olduğu bildirilmektedir (Sharangi, 2009).

Antioksidanlar, sağlık açısından olumlu etkileri olan önemli bileşenlerdendir (Öğüt, 2014). Antioksidanca zengin fonksiyonel gıdaları günlük olarak düzenli tüketmenin sağlıklı doğal beslenme açısından önemli olduğu aşikardır (Yılmaz, 2010). Ülkemizde sudan sonra en fazla tüketilen içecek olan çaydan bu doğrultuda istifade edilmek suretiyle vücutta antioksidan kapasitesini de artırmak mümkün olabilmektedir (Van ve ark., 1997). Antioksidan kapasitesi yüksek çayların elde edilmesinde ise, bu anlamda yüksek potansiyele sahip kaliteli genotiplerin uygun ekolojilerde yetiştirilmesi, budama ve gübreleme gibi bakım işlemlerinin usulüne uygun yapılması ve hassasiyet gösterilerek uygun zamanda hasadı yapılan genç sürgünlerin kalite kaybına uğramadan işlenmek üzere fabrikaya getirilmesi ile mümkün olabilmektedir.

Önemli bakım işlemlerinden bir tanesi olan budamanın verim ve kalite üzerindeki etkisi de büyük olmaktadır. Yapılan çalışmalarda, budamayı takiben 3 . yılda çay veriminin maksimuma çıktığı (De Costa ve ark., 2009; Kumar ve ark., 2015) ve antioksidan etki gösteren birtakım bileşenlerin miktarlarında değişmeler olduğu bildirilmektedir. Ravichandran (2004) tarafindan yürütülen bir çalışmada, budamayı takiben $0,1 ., 2$. ve 3 . yıl 2,5 yaprak üzerinden toplanılan yeşil yaprakların toplam fenol ve kateşin içerikleri belirlenmiş, bu içeriklerin birinci yıl artış gösterdiği bundan sonra da azalmaya başladığı bildirilmiştir. Ayrıca bu araştırmada, yapraklardaki klorofil içeriği budama zamanından itibaren artma göstermiştir. Toplam karotenoidler 2 yaşına kadar artmış, sonrasında düşme göstermiştir. Aynı şekilde Yilmaz ve ark. (2004), çay yapraklarındaki polifenol içeriğinin budamadan itibaren geçen her y1l giderek azaldığını; en yüksek içeriğin 1 . ve 2 . yıl elde edilebildiğini bildirmektedirler. Aynı araştırmacılar, polifenol içeriği bakımından ilk 2 hasat döneminde 3 . hasat dönemine göre daha yüksek değerler elde etmişlerdir.
Ercisli ve ark. (2008), Rize'de Derepazarı çay klonuna ait bitkilerden 3 sürgün döneminde (15 Mayıs, 15 Temmuz ve 15 Eylül) hasat ettikleri çay yaprakları üzerinde yaptıkları bir çalışmada, $\beta$-karoten bleaching metoduna göre antioksidan aktivitesinin ilk hasatta $\% 84,43 ; 2$. hasatta $\% 89,27$ ve 3 . hasatta $\% 85,17$ olarak tespit etmişlerdir.

Faydalı antioksidanların kaynağı olarak görülen yeşil çay taze yaprakların fermente edilmeden işlenmesiyle elde edildiğinden, bu çay tipine en yakın sonuçlar da şüphesiz taze çay yapraklarının analizi ile elde edilebilmektedir (Graham, 1992). Çay yapraklarının toplanmasında yeni bir bakış açısı oluşturmak üzere yaptığımız bu çalışma, organik çay tarımında budama yaşı ve hasat saatlerine bağlı olarak toplanan taze çay yapraklarının antioksidan aktivitesi ve kuru madde oranı bakımından farklılıkları ortaya koymak amaciyla yürütülmüştür.

\section{Materyal ve Metot}

$\mathrm{Bu}$ araştırma, 2016 yılında Hemşin İlçesi Bilen Köyü'nde organik çay tarımı yapılan ve 523 m rakımda bulunan 40 yaşındaki bir çaylıkta yürütülmüştür. Birbirine benzer özellik gösteren toplam 9 bitki üzerinde yürütülen çalışmada, budama yaşı (budamadan sonraki 1. yıl, 3. yıl ve 5. yıl) ve gün içi hasat saatlerinin (sabah/07.므, öğle/12. $\underline{00}$ ve akşam 17. $\underline{00}$ ) taze çay yapraklarında antioksidan aktivitesi üzerine etkisi belirlenmeye çalışılmıştır.

Çalışmanın yürütüldüğü deneme alanından alınan toprak örnekleri, Rize İli Pazar İlçesi'nde bulunan ilgili Bakanlıkça yetkili bir laboratuvarda (Ş. Şemsi Bayraktar Toprak Analiz Laboratuvarı) analiz edilmiştir. Deneme alanına ait toprak analiz sonuçları incelendiğinde; toprakların tuzluluk değeri ve kireç oranı bakımından düşük değerler gösterdiği ve killi özellikte olduğu anlaşılmaktadır (Çizelge 1). Organik madde miktarı, fosfor ve potasyum içeriği yeterli olan deneme toprağ kuvvetli asit reaksiyonu göstermiş olup, çalışmanın yapıldığı yıl üretici tarafından bir gübre uygulaması yapılmamıştır.

Çizelge 1 Araştırmanın yürütüldüğü deneme arazisine ait toprak özellikleri

Table 1 Soil properties of the trial land where the research was conducted

\begin{tabular}{l|c}
\multicolumn{1}{c|}{ Toprak özellikleri } & Değerler \\
\hline Toprak Tekstürü & Killi \\
Saturasyon Oranı (\%) & 75,00 \\
Kireç Oranı (\%) & 0,10 \\
Tuzluluk Değeri (Ds/m) & 0,67 \\
Topak Reaksiyonu (pH) & 4,98 \\
Organik Madde Oranı (\%) & 3,05 \\
Elverişli $\mathrm{P}_{2} \mathrm{O}_{5}(\mathrm{mg} / \mathrm{kg})$ & 8,67 \\
Değişebilir $\mathrm{K}_{2} \mathrm{O}(\mathrm{kg} / \mathrm{da})$ & 48,36 \\
\hline
\end{tabular}

Çay örnekleri, sırasıyla 11/05/2016, 30/06/2016 ve 10/08/2016 tarihlerinde 2,5 yaprak üzerinden toplanmıştır. Malezya'da yürütülen bir çalışmada; fenolik içeriği ve antioksidan aktivitesi bakımından sarımsı yeşil 
renkteki taze yaprakların (2 yaprak ve 1 tomurcuk) açık yeşil renkteki taze yapraklar (3., 4. ve 5. yapraklar) ile birbirine benzer özellik gösterdiği; bununla birlikte koyu yeşil renkteki olgun yapraklardan (6., 7. ve 8. yapraklar) daha üstün olduğu belirlenmiştir (Chan ve ark., 2007). Rize'de yürütülen mevcut çalışmada, 2,5 yaprak toplanarak antioksidan aktivitenin ulaşabileceği maksimum potansiyel belirlenmeye çalışılmıştır.

Hasat edilen yapraklar, analiz edilinceye kadar $18^{\circ} \mathrm{C}$ 'de tutulmuştur. Daha sonra liofilizatörde kurutulan yapraklar toz haline getirilmiş ve homojenize edilerek analiz için hazırlanmıştır. Hasat edilen materyallerden 3 'er tekerrür halinde alınan örnekler $103 \pm 2^{\circ} \mathrm{C}$ 'de tamamen kuruyuncaya kadar etüvde bekletilerek, yaş ağırlık üzerinden kuru madde oranları hesaplanmıştır.

Örneklerin analizinde Izzreen ve Fadzelly (2013)'nın kullandığı yöntem modifiye edilerek uygulanmıştır. Bir orbital çalkalayıcı kullanılarak her $0,1 \mathrm{~g}$ kurutulmuş örnek $10 \mathrm{ml}$ metanolde (\%80) 1 saat süreyle ekstrakte edilmiştir. Örnek-çözücü karışımı 20 dakika boyunca 4000 devir/dak. santrifüj edilmiştir. Süpernantlar karışımdan alınmış ve analiz edilinceye kadar $-18^{\circ} \mathrm{C}$ 'de saklanmıştır. Daha sonra örneklerin toplam antioksidan kapasiteleri FRAP (Demir indirgenme antioksidan kapasitesi) yöntemi ile belirlenmiştir.

FRAP ayıracı olarak $200 \mathrm{ml}$ acetate buffer (pH 3,6), $20 \mathrm{ml}$ 2,4,6-tripyridyl-s-triazine (TPTZ) solusyonu ve 20 $\mathrm{ml}$ demir klorid $\left(\mathrm{FeCl}_{3} \cdot 6 \mathrm{H}_{2} \mathrm{O}\right)$ çözeltileri 10:1:1 oranlarında karıştırılarak tampon çözelti hazırlanmıştır. Tampon çözelti hazırlanırken bu kimyasalların çözünmesinde HCI kullanılmıştır. Toplam $1980 \mu \mathrm{l}$ FRAP ayırac1 $+20 \mu 1$ örnek olacak şekilde hazırlanan numuneler küvete eklenerek UV Spectrofotometrede $593 \mathrm{~nm}$ dalga boyunda absorbans değeri okunmuştur. 4 farklı konsantrasyon değeri $(5 \mu \mathrm{l}, 10 \mu \mathrm{l}, 15 \mu \mathrm{l}$ ve $20 \mu \mathrm{l})$ kullanılarak bilinen $\quad \mathrm{Fe} \quad$ (II) (FeSO4) konsantrasyonlarından bir standart elde edilmiştir. Kullanılan konsantrasyonlara karşılık gelen her standardın FRAP değeri işaretlenerek grafik çizilmiş; standart eğri kullanılarak örneklere ait ölçülen FRAP değerleri, demir indirgenme kabiliyetine sahip antioksidanın konsantrasyonu olarak belirlenmiştir (Şekil 1). Kurutulmuş $1 \mathrm{~g}$ çay yaprağının antioksidan gücü ise $\mu \mathrm{mol}$ olarak $\mathrm{FeSO}_{4}$ cinsinden hesaplanmıştır.

Çalışmada antioksidan aktivitesi olarak elde edilen veriler, JMP istatistik programı kullanılarak analiz edilmiştir. Ortalamaların karşılaştırılmasında ise Tukey testi uygulanmıştır.

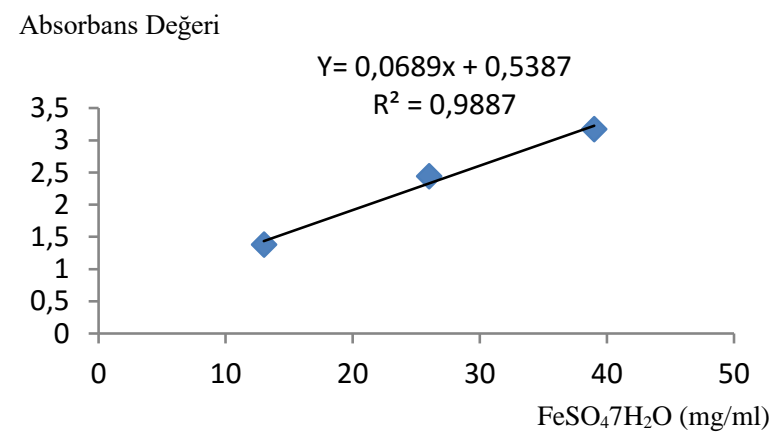

Şekil 1 FRAP Tayini için kalibrasyon grafiği Figure 1 Calibration graphic for FRAP analysis

\section{Bulgular ve Tartışma}

Organik çay tarımı yapılan arazide budama yaşı ve diurnal varyabilitenin incelendiği çalışmada, toplanan taze çay yapraklarının antioksidan aktivitesi genel olarak 2258,5-7229,2 $\mu \mathrm{mol} \quad \mathrm{FeSO}_{4} / \mathrm{g} \quad \mathrm{km}$ arasında değişim göstermiştir.

1. ve 3. sürgün döneminde budama yaşının, incelenen özellik üzerindeki etkisi çok önemli $(\mathrm{P}<0,01)$ çıkarken; 2 . sürgün döneminde antioksidan aktivitesi bakımından ölçülen değerler arasındaki farklılıklar istatistiki anlamda önemsiz olmuştur (Çizelge 2). Mevcut çalışmada 3. hasat döneminde diğer dönemlere göre çok daha yüksek antioksidan değerler tespit edilmiştir. Buna karşılık, Ercisli ve ark., (2008), 2. hasat döneminde bu değerlerin daha yüksek olduğunu saptamışlardır. Antioksidan kapasitesinin hasat zamanına göre değişiklik gösterdiğine yönelik sonuçlar, çaydan başka farklı bitkilerde de mevcuttur. Örneğin, Phuntsog ve ark., (2017), Hippophae rhamnoides yapraklarındaki antioksidan aktivitesinin; Ozkan ve ve ark., (2010) ise Origanum onites kekiğinden elde edilen esansiyel yağlarındaki antioksidan aktivitesinin, bitkilerin vejetatif peryoduna bağlı olarak aylara göre değişkenlik gösterdiğini saptamışlardır.

İlk sürgün döneminde en yüksek antioksidan aktivitesi, 4991,1 $\mu \mathrm{mol} \quad \mathrm{FeSO}_{4} / \mathrm{g} \quad \mathrm{km} \quad(\mathrm{P}<0,01)$ ile budamadan itibaren 3 . gelişme döneminde olan bitkilerden elde edilmiştir. Beşinci budama yaşında tespit edilen bu ani değer yükselişi, örneklerin alındığı dönemde diğerlerine oranla fazla sayıda daha genç yapraklara sahip olmasından kaynaklanmış olabilir. Üçüncü sürgün döneminde, diğer dönemlere göre yapraklardaki antioksidan aktivitesi çok daha yüksek çıkmıştır. Üçüncü sürgün döneminde incelenen özellik bakımından en yüksek değer, 7229,2 $\mu$ mol $\mathrm{FeSO}_{4} / \mathrm{g} \mathrm{km}$ ile 1. budama yaşında olan bitkilerden elde edilmiştir (Çizelge 2; Şekil 2).

Thomas ve ark., (2005) kateşin fraksiyonlarının ve gallik asidin budamayı takiben 3. yıla kadar arttığı, ancak 4. yıl aniden düştüğünü saptamışlardır. Araştırmacıların elde ettiği değerler budama yaşına bağlı olarak değişiklik göstermekte olup; mevcut çalışma sonuçları ile bu açıdan benzerlik göstermektedir. Aynı benzerlik, Ravichandran (2004) tarafından yürütülen çalışmada da görülmektedir. Ayrıca, Yilmaz ve ark. (2004) çay yapraklarındaki polifenol içeriğinin budamadan itibaren geçen her y1l giderek azaldığını; en yüksek içeriğin 1. ve 2. yıl elde edildiğini bildirmektedirler. Hasat dönemleri dikkate alındığında ise ilk iki hasat döneminde, 3. hasat dönemine göre daha yüksek değerler elde etmişlerdir.

Genç çay yapraklarında en güçlü antioksidan olan ve yüksek düzeylerde bulunan EGCG (Epigallokateşin Gallat) ve yine bol miktarlarda bulunan ECG (Epikateşin Gallat)'den dolayı, yeşil çaydaki antioksidan aktivitesinin beyaz çaydakine benzerlik gösterdiği bildirilmektedir (Karori ve ark., 2007). Bununla birlikte, biyolojik özellikleri açısından çayın kalite parametreleri arasında yer alan toplam polifenol içeriği ve antioksidan kapasitesi arasında yüksek bir korelasyonun bulunduğu bilinmektedir (Anesini ve ark., 2008; Mo Ku ve ark., 2010). Bu özellikler ise yetiştirilen genotiplere (Thomas ve ark., 2005), çayın tipine (Karori ve ark., 2007; Tounekti ve ark., 2013), üretim lokasyonuna, mevsim özellikleri, yükseklik ve 1şık yoğunluğu gibi çevresel faktörlerdeki çeşitliliğe bağlı olarak değişmekte; toplama standartları ve sıklığı, budama sıklığı gibi çeşitli tarımsal 
faktörler de çayın antioksidan kalitesini etkilemektedir (Tosun ve Karadeniz, 2005; Kaur ve ark., 2014).

Deneme verilerinin ortalaması dikkate alındığında, akşam saatinde (17. $\underline{00})$ toplanan yapraklardaki antioksidan aktivitesinin, sabah $(07 . \underline{00})$ ve öğle saatlerinde (12.0ㅜ) toplanan yapraklardakine göre daha yüksek çıktığı belirlenmiştir (Şekil 3). Genel ortalama olarak, sabah toplanan çay yapraklarında antioksidan aktivitesi 4121,3 $\mu \mathrm{mol} \mathrm{FeSO}_{4} / \mathrm{g} \mathrm{km}$ iken, bu değer öğle saatinde az bir artışla 4.140,1 $\mu \mathrm{mol} \mathrm{FeSO}_{4} / \mathrm{g} \mathrm{km}^{2}$, akşam saatinde ise 4276,8 $\mu \mathrm{mol} \mathrm{FeSO}_{4} / \mathrm{g}$ km'e yükselmiştir (Çizelge 3).

Mevcut araştırmada, budama yaşı ve hasat zamanına bağlı olarak kuru madde oranındaki değişimler de incelenmiştir. Denemede elde edilen verilere göre, budamadan itibaren geçen yıllar dikkate alındığında, en yüksek kuru madde oranı ortalama $\% 28,80$ ile 2 . sürgün döneminde gerçekleşmiş, onu sırasıyla \%25,15 ile 3 . sürgün ve \%20,17 ile 1 . sürgün dönemi takip etmiştir (Çizelge 4). Çalışmada elde edilen kuru madde değerleri, genel olarak Yilmaz ve ark. (2004)'nın elde ettiği değerlere yakın değerlerdir. Ancak, sürgün dönemlerine ait ortalama kuru madde oranlarında farklılık görülmektedir. Nitekim, mevcut çalışmada en yüksek kuru madde oran1 2. sürgün döneminde tespit edilirken, Yilmaz ve ark. (2004)'nın yürüttüğü çalışmada en yüksek ortalama değer, 1. sürgün dönemine ait olmuştur.

En yüksek kuru madde oran1, 1. sürgün döneminde $(\mathrm{P}<0,05)$ bitkilerin 1 . ve 5 . budama yaşında gözlenlenirken; 2. sürgün $(\mathrm{P}<0,01)$ ve 3 . sürgün $(\mathrm{P}<0,05)$ dönemlerinde ise bitkilerin 3 . ve 5 . budama yaşlarında elde edilmiştir. Dolayısıyla 5. gelişme yılında olan bitkilerin taze yaprakları, tüm sürgün dönemlerinde de yüksek düzeyde kuru madde içeriğine sahip olmuştur (Şekil 4). Yilmaz ve ark., (2004) 5 yıllık bir budama döngüsünde budamayı takip eden yıllarda yapraktaki kuru madde oranlarının 3. yıldan itibaren istatistiki anlamda bir artış gösterdiğini; 3, 4 ve 5. yıllarda elde edilen veriler arasında görülen farklılığın ise önemsiz olduğunu saptamışlardır. Genel olarak elde edilen bu sonuçlar, mevcut çalışma ile benzerlik göstermektedir.

Çizelge 2 Farklı budama yaşlarına (B1, B3 ve B5) göre toplanan taze çay yapraklarının antioksidan aktivitesindeki değişim Table 2 The variation in antioxidant activity of fresh tea leaves collected depending on different pruning age (B1, B3 and B5)

\begin{tabular}{l|ccc}
\hline \multirow{2}{*}{ Budama Yaş1 } & \multicolumn{3}{|c}{ Antioksidan aktivitesi ( $\mu$ mol FeSO $4 / \mathrm{g}$ kuru madde) } \\
\cline { 2 - 3 } & 1. Sürgün & 2 Sürgün & 3 . Sürgün \\
\hline B1 & $2496,3^{\mathrm{b}}$ & 2442,1 & $7229,2^{\mathrm{a}}$ \\
B3 & $2584,5^{\mathrm{b}}$ & 2258,5 & $7164,6^{\mathrm{b}}$ \\
B5 & $4991,1^{\mathrm{a}}$ & 2593,9 & $7153,6^{\mathrm{b}}$ \\
Ortalama & 3357,3 & 2431,5 & 7182,5 \\
F değerleri & $* * \mathrm{~F}=18,57$ & $\mathrm{~F}=1,00$ & $* * \mathrm{~F}=9,09$ \\
CV & $\% 21,9$ & $\% 15,4$ & $\% 0,4$ \\
\hline
\end{tabular}

Aynı harfle gösterilen ortalamalar arasında $* * \mathrm{P}<0,01$ olasıllkla farkl1l1k yoktur.

Çizelge 3 Gün içi hasat saatlerine $(07.00,12.00$ ve 17.00) göre toplanan taze çay yapraklarının antioksidan aktivitesindeki değişim ve $( \pm)$ standart sapma değerleri

Table 3 The variation in antioxidant activity of fresh tea leaves collected depending on intraday harvest time (07.00, 12.00 and 17.00) and the ( \pm ) standard deviation values

\begin{tabular}{|c|c|c|c|c|c|c|c|}
\hline \multirow{2}{*}{$\begin{array}{c}\text { Hasat Zamanı } \\
\text { (Saat) }\end{array}$} & \multicolumn{6}{|c|}{ Antioksidan aktivitesi $\left(\mu \mathrm{mol} \mathrm{FeSO}_{4} / \mathrm{g} \mathrm{km}\right)$} & \multirow{2}{*}{ Ortalama } \\
\hline & \multicolumn{2}{|c|}{ 1. Sürgün } & \multicolumn{2}{|c|}{ 2. Sürgün } & \multicolumn{2}{|c|}{ 3. Sürgün } & \\
\hline $07 . \underline{00}$ & 3097,0 & $\pm 471,1$ & 2065,4 & $\pm 208,2$ & 7201,5 & $\pm 12,8$ & 4121,3 \\
\hline $12 . \underline{00}$ & 2920,9 & $\pm 651,4$ & 2349,3 & $\pm 246,9$ & 7150,0 & $\pm 55,7$ & 4140,2 \\
\hline $17 . \underline{00}$ & 3134,8 & $\pm 753,0$ & 2491,8 & \pm 181.0 & 7203,8 & $\pm 49,4$ & 4276,8 \\
\hline Ort. & 3050,9 & $\pm 563,0$ & 2302,2 & $\pm 267,6$ & 7185,1 & $\pm 46,6$ & 4179,4 \\
\hline
\end{tabular}

Çizelge 4 Budama yaşına (B1, B3 ve B5) ve hasat saatlerine göre toplanan taze çay yapraklarının kuru madde oranındaki değişim

Table 4 The variation in the dry matter rate of fresh tea leaves collected depending on pruning age (B1, B3 and B5) and harvest time

\begin{tabular}{|c|c|c|c|c|c|c|}
\hline \multirow{2}{*}{$\begin{array}{l}\text { Sürgün } \\
\text { Dönemi }\end{array}$} & \multirow{2}{*}{$\begin{array}{l}\text { Hasat Zamanı } \\
\text { (Saat) }\end{array}$} & \multicolumn{4}{|c|}{ Kuru Madde Oranı $(\%)$} & \multirow{2}{*}{$\begin{array}{c}\text { Hesaplanan F } \\
\text { Değerleri }\end{array}$} \\
\hline & & B1 & B3 & B5 & Ortalama & \\
\hline \multirow{4}{*}{ 1. Sürgün } & $07^{00} \underline{-1}$ & 19,43 & 18,67 & 20,23 & $19,44^{\mathrm{b}}$ & $\mathrm{B} *(\mathrm{~F}=9,74)$ \\
\hline & $12 . \underline{00}$ & 21,03 & 20,17 & 20,37 & $20,52^{\mathrm{a}}$ & $\mathrm{HS}^{* *}(\mathrm{~F}=13,56)$ \\
\hline & $17 . \underline{00}$ & 20,17 & 19,77 & 21,73 & $20,56^{\mathrm{a}}$ & $\mathrm{B} \times \mathrm{HS}(\mathrm{F}=4,16)$ \\
\hline & Ortalama & $20,21^{\mathrm{ab}}$ & $19,53^{\mathrm{b}}$ & $20,78^{\mathrm{a}}$ & 20,17 & $\mathrm{CV}=\% 2,55$ \\
\hline \multirow{4}{*}{ 2. Sürgün } & $07 \underline{00}$ & $26,37^{\mathrm{b}}$ & $29,30^{\mathrm{a}}$ & $29,37^{\mathrm{a}}$ & $28,34^{\mathrm{b}}$ & $\mathrm{B} * *(\mathrm{~F}=48,55)$ \\
\hline & $12 . \underline{00}$ & $29,27^{\mathrm{a}}$ & $30,93^{\mathrm{a}}$ & $28,87^{\mathrm{a}}$ & $29,69^{\mathrm{a}}$ & $\mathrm{HS}^{* *}(\mathrm{~F}=9,52)$ \\
\hline & $17 . \underline{00}$ & $24,73^{\mathrm{b}}$ & $29,97^{\mathrm{a}}$ & $30,43^{\mathrm{a}}$ & $28,37^{\mathrm{b}}$ & $\mathrm{B} \times \mathrm{HS}^{* *}(\mathrm{~F}=13,02)$ \\
\hline & Ortalama & $26,79^{\mathrm{b}}$ & $30,07^{\mathrm{a}}$ & $29,56^{\mathrm{a}}$ & 28,80 & $\mathrm{CV}=\% 2,59$ \\
\hline \multirow{5}{*}{ 3. Sürgün } & $07 \underline{00}$ & $23,23^{\mathrm{bc}}$ & $27,27^{\mathrm{ab}}$ & $26,07^{\mathrm{abc}}$ & 25,52 & $\mathrm{~B} *(\mathrm{~F}=13,25)$ \\
\hline & $12 . \underline{00}$ & $22,40^{\mathrm{c}}$ & $26,50^{\mathrm{abc}}$ & $28,17^{\mathrm{a}}$ & 25,69 & $\mathrm{HS}(\mathrm{F}=2,24)$ \\
\hline & $17 . \underline{00}$ & $24,40^{\mathrm{abc}}$ & $24,50^{\mathrm{abc}}$ & $23,83^{\mathrm{abc}}$ & 24,24 & $\mathrm{~B} \times \mathrm{HS} *(\mathrm{~F}=3,51)$ \\
\hline & Ortalama & $23,34^{\mathrm{b}}$ & $26,09^{\mathrm{a}}$ & $26,02^{\mathrm{a}}$ & 25,15 & $\mathrm{CV}=\% 6,30$ \\
\hline & Genel ortalama & 23,45 & 25,23 & 25,45 & 24,71 & \\
\hline
\end{tabular}




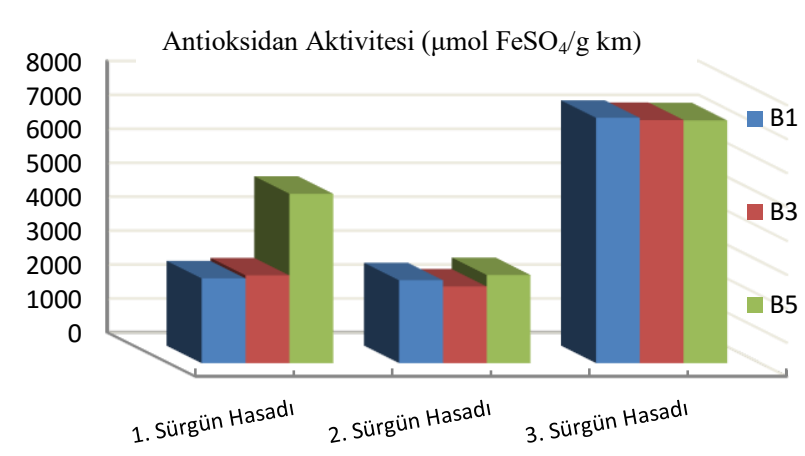

Şekil 2 Budama yaşına (B1, B3 ve B5) göre toplanan taze çay yapraklarının antioksidan aktivitesindeki değişim

Figure 2 The variation in antioxidant activity of fresh tea leaves collected depending on pruning age (B1, B3 and B5)

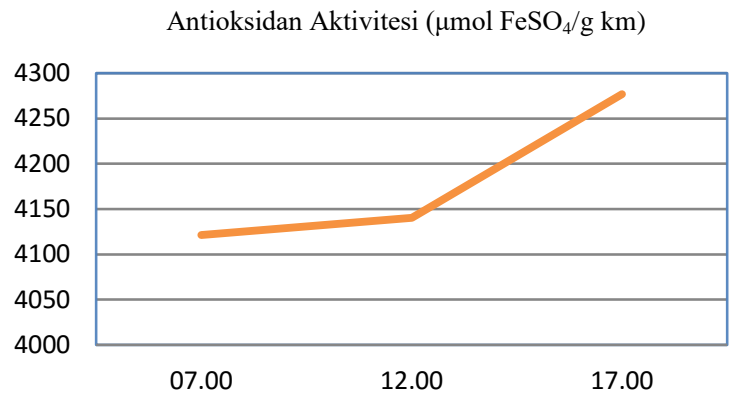

Hasat zamanı (Saat)

Şekil 3 Taze çay yapraklarının antioкsıuaı аки vııеsıııı hasat saatine bağlı olarak değişimi

Figure 3 The variation in antioxidant activity of fresh tea leaves depending on harvest time

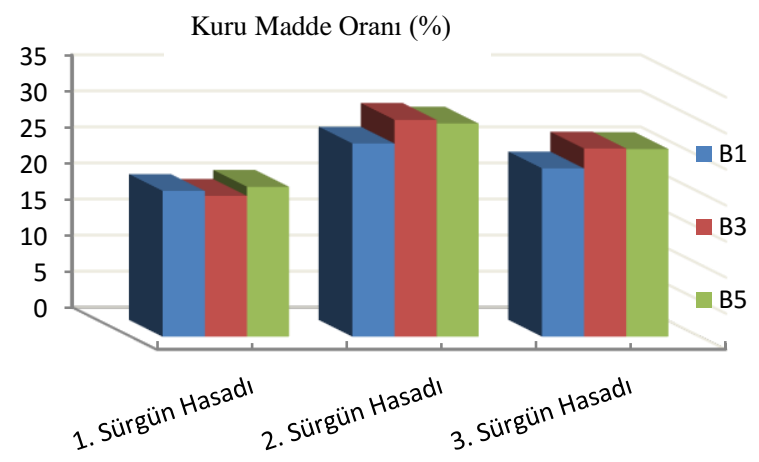

Şekil 4 Budama yaşına (B1, B3 ve B5) göre toplanan taze çay yapraklarının kuru madde oranındaki değişim

Figure 4 The variation in dry matter rate of fresh tea leaves collected depending on pruning age (B1, B3 and B5)

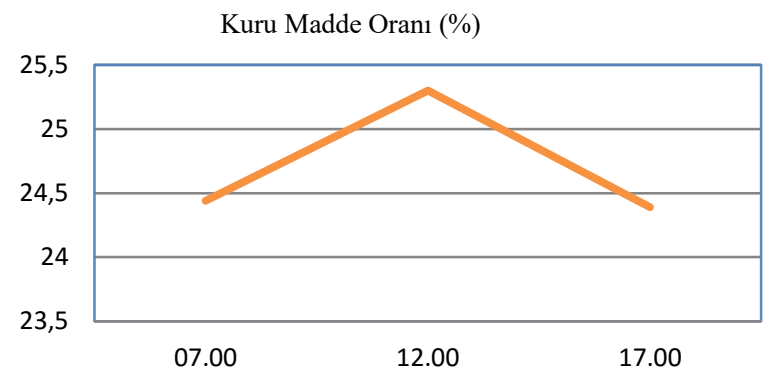

Şekil 5 Taze çay yapraklarında kuru madde oranının hasat saatine bağlı olarak değişimi

Figure 5 The variation in dry matter rate of fresh tea leaves depending on harvest time
Hasat zamanının kuru madde üzerindeki etkisi 1. ve 2. sürgün döneminde çok önemli $(\mathrm{P}<0,01) ; 3$. sürgün döneminde ise önemsiz çıkmıştır. Birinci sürgün döneminde öğle ve akşam saatinde en yüksek kuru madde değerleri elde edilmiştir. İkinci sürgün döneminde ise en yüksek kuru madde oranı sadece öğlen saatinde elde edilmiş, sabah ve akşam saatlerinde tespit edilen kuru madde oranları arasında ise istatistiki anlamda bir farkl111k bulunmamıştır.

Budama yaşı $\times$ hasat zamanı interaksiyonu dikkate alındığında, incelenen özellik bakımından görülen farkl1lıklar 1. sürgün döneminde istatistiki anlamda önemsiz çıkarken; 2. sürgün döneminde çok önemli $(\mathrm{P}<0,01)$, 3. sürgün döneminde ise önemli $(\mathrm{P}<0,05)$ olmuştur. Kuru madde oranları bakımından gerek 2 . sürgün gerekse 3 . sürgün döneminde, 3. ve 5 . budama yaşının hasat zamanları ile olan tüm interaksiyonları arasında istatistiki anlamda bir farklılık bulunmamıştır. Bununla birlikte, 1. budama yaşının 2. sürgün döneminde öğle saati interaksiyonu ve 3 . sürgün dönemindeki akşam saati interaksiyonu yukarıda ifade edilen istatistik grupları içinde yer almıştır.

Deneme verilerinin ortalaması dikkate alındığında, öğle saatinde toplanan yapraklarda kuru madde oranının sabah ve akşam saatlerinde toplanan yapraklardakine göre daha yüksek olduğu belirlenmiştir (Şekil 5). Ortalama kuru madde oranı sabah ve akşam saatlerinde sırasıyla $\% 24,44$ ve $\% 24,39$ olarak tespit edilmiştir. Öğle saatinde ise bu değer \%25,30'a yükselmiştir.

Benzie ve Szeto (1999) tarafindan farklı çay tiplerinin (Camellia sinensis) antioksidan gücünün tespitine yönelik yapılan bir araştırmada, 25 çeşit çayın yeni hazırlanmış infüzyonlarının analizi sonucunda, çayın antioksidan kapasitesinin toplam fenolik içeriğiyle kuvvetli bir ilişki $(\mathrm{r}=0,956)$ içinde olduğu belirlenmiştir. Çalışmada, kurutulmuş $1 \mathrm{~g}$ çay yaprağının antioksidan gücü $\mu \mathrm{mol}$ olarak ifade edilmiş ve bu değer, siyah çaylarda 132-654 $\mu \mathrm{mol} / \mathrm{g}$, oolong çaylarda $233-532 \mu \mathrm{mol} / \mathrm{g}$ ve yeşil çayda $272-1144 \mu \mathrm{mol} / \mathrm{g}$ olarak askorbik asit cinsinde tespit edilmiştir.

Antioksidan aktivitesi bakımından siyah çayın yeşil çaya göre daha iyi olduğunu gösteren araştırmalar olduğu gibi, bu konuda herhangi bir önemli farklılığın olmadığı yönünde de raporlar bulunmaktadır. Ancak genel olarak, antioksidan değeri, yeşil çayda daha yüksek (Khalaf ve ark., 2008; Carloni ve ark., 2013) olup; onu sirasiyla oolong çay ve siyah çay izlemektedir. Çayın tipi, büyüme koşulları (mevsim, iklim, toprak), uygulama farklı1ıkları (mekanik veya elle toplama, yaprakların yaşı) ve çayın işlenmesinde uygulanan farklı teknolojilere bağlı olarak çayın bileşenlerine etki eden birçok değişken, bu çelişkili sonuçlara neden olmaktadır. Dolayısıyla, bu değişkenler minimize edilmeden siyah, yeşil ve beyaz çayın antioksidan aktivitelerini karşılaştırmak kesinlikle doğru değildir (Carloni ve ark., 2013; Unachukwu ve ark., 2010).

İçerdiği flavonoller sayesinde güçlü antioksidan aktiviteye sahip olan ve yaygın olarak tüketilen polifenolik bir içecek olan çay, antioksidan maddelerce zengin olması nedeniyle insan sağlı̆̆ına olumlu katkı sağlamada önemli bir rol oynayabilir (Karori ve ark., 2007). Diğer bir ifade ile çay, antioksidan aktiviteye sahip polifenollerin ve mineraller ile önemli bir diyet kaynağ 
olabilir. Dolayısıyla, böyle güçlü bir potansiyele sahip çayda antioksidan aktivitesi gösteren unsurların varlığından istifade edilebilmesine yönelik çalışmaların tasarlanmasına ihtiyaç vardır (Cabrera ve ark., 2003).

Sonuç olarak, organik çay tarımında budama yaşı ve diurnal varyabilitenin taze çay (Camellia sinensis (L.) O. Kuntz) yaprakları üzerindeki etkisinin ele alındığı bu çalışmada; yaprakların antioksidan aktivitesi ve kuru madde oranı, budama yaşı ve hasat zamanına bağlı olarak değişmiş ve sürgün dönemlerine göre de farklılık göstermiştir. Antioksidan aktivitesi bakımından en yüksek değerler 3. sürgün döneminde alınmış ve genel ortalama olarak akşam saatinde toplanan yapraklardan daha yüksek değerler elde edilmiştir. Araştırmada elde edilen sonuçlar, daha fonksiyonel çay üretiminde, budama yaşı ve diurnal varyabilitenin de dikkate alınarak arzu edilen nitelikte ürün alınabileceğine ilişkin yeni veriler ortaya koymaktadir.

\section{Teșekkür}

Yaprak örneklerinin alınmasında uygun arazinin tespitine yönelik katkılarından dolayı Hemşin Gıda Tarım ve Hayvancılık İlçe Müdürü Sayın Dursun Ali AKPINAR'a teşekkür ederiz.

\section{Kaynaklar}

Anesini C, Ferraro GE, Filip R. 2008. Total polyphenol content and antioxidant capacity of commercially available tea (Camellia sinensis) in Argentina. Journal of Agricultural and Food Chemistry, 56: 9225-9229.

Benzie IFF, Szeto YT. 1999. Total antioxidant capacity of teas by the ferric reducing/antioxidant power assay. Journal of Agricultural and Food Chemistry, 47: 633-636.

Cabrera, C, Gieänez R, Loäpez C. 2003. Determination of tea components with antioxidant activity. Journal of Agricultural and Food Chemistry, 51: 4427-4435.

Carloni P, Tiano L, Padella L, Bacchetti T, Customu C, Kay A, Damiani E. 2013. Antioxidant activity of white, green and black tea obtained from the same tea cultivar. Food Research International, 53: 900-908.

Chan EWC, Lim YY, Chew YL. 2007. Antioxidant activity of Camellia sinensis leaves and tea from a lowland plantation in Malaysia. Food Chemistry, 102:1214-1222.

ÇAYKUR. 2016. İstatistik Bülten http://www.caykur.gov.tr/CMS/Design/Sources/

2016. Dosya/Yayinlar/201.pdf (26.12.2017).

De Costa WAJM, Navaratne DMS, Anandacoomaraswamy A. 2009. Physiological basis of yield variation of tea (Camellia sinensis) during different years of the pruning cycle in the central highlands of Sri Lanka. Experimental Agriculture, 45:429-450.

Ercisli S, Orhan E, Ozdemir O, Sengul M, Gungor N. 2008. Seasonal variation of total phenolic, antioxidant activity, plant nutritional elements, and fatty acids in tea leaves (Camellia sinensis var. sinensis clone Derepazari 7) grown in Turkey. Pharmaceutical Biology, 46: 683-687.

FAO. 2015. World tea production and trade current and future development. Food And Agriculture Organization of The United Nations, Rome.

Graham HN. 1992. Green tea composition, consumption, and polyphenol chemistry. Preventive Medicine, 21(3): 334-350.
Izzreen MNNQ, Fadzelly ABM. 2013. Phytochemicals and antioxidant properties of different parts of Camellia sinensis leaves from sabah tea plantation in Sabah, Malaysia. International Food Research Journal, 20(1): 307-312.

Karori SM, Wachira FN, Wanyoko JK, Ngure RM. 2007. Antioxidant capacity of different types of tea products. African Journal of Biotechnology, 6(19): 2287-2296.

Kaur L, Jayasekera S, Moughan PJ. 2014. Antioxidant quality of tea (Camellia sinensis) as affected by environmental factors. V.P. (ed.) Processing and Impact on Antioxidants in Beverages, Chapter 13, p:121-129, Academic Press publications.

Khalaf NA, Shakya AK, Al-Othman A, El-Agbar Z, Farah H. 2008. Antioxidant activity of some common plants. Turkish Journal of Biology, 32: 51-55.

Kumar R, Bisen JS, Singh M, Bera B. 2015. Effect of pruning and skiffing on growth and productivity of Darjeeling tea (Camellia sinensis L.). International Journal of Technical Research and Applications, 3(3): 28-34.

Mo Ku K, Choi JN, Kim J, Kim JK, Yoo LG, Lee SJ, YoungShick Hong YS, Lee CH. 2010. Metabolomics analysis reveals the compositional differences of shade grown tea (Camellia sinensis L.). Journal of Agricultural and Food Chemistry, 58(1): 418-426.

Yılmaz İ. 2010. Antioksidan içeren bazı gıdalar ve oksidatif stres. İnönü Üniversitesi T1p Fakültesi Dergisi, 17(2): 143153.

Ozkan G, Baydar H, Erbas S. 2010. The influence of harvest time on essential oil composition, phenolic constituents and antioxidant properties of Turkish oregano (Origanum onites L.). Journal of Science and Food Agriculture, 90: 205-209.

Öğüt S. 2014. Doğal antioksidanların önemi. Adnan Menderes Üniversitesi Ziraat Fakültesi Dergisi, 11(1): 25-30.

Phuntsog D, Diskit D, Stanzin A, Anil A, Bhuvnesh K, Tsering S. 2017. Sexual differences and seasonal variations in total phenolics and antioxidant properties in Hippophae rhamnoides leaves. Journal of Berry Research, 7(1): 61-69.

Ravichandran R. 2004. The impact of pruning and time from pruning on quality and aroma constituents of black tea. Food Chemistry, 84: 7-11.

Sharangi AB. 2009. Medicinal and therapeutic potentialities of tea (Camellia sinensis L.)- A review. Food Research International, 42: 529-535.

Thomas J, Saravanan M, Kumar RR, Pius PK. 2005. Influence of age after pruning on the levels of flavanols and other bioconstituents in tea (Camellia sinensis). Journal of the Science of Food and Agriculture, 85: 931-934.

Tosun İ, Karadeniz B. 2005. Çay ve çay fenoliklerinin antioksidan aktivitesi. OMÜ Ziraat Fakültesi Dergisi, 20(1): 78-83.

Tounekti T, Joubert E, Hernández I, Munné-Bosch S. 2013. Improving the polyphenol content of tea, Journal Critical Reviews in Plant Sciences, 32(3): 192-215.

Unachukwu UJ, Ahmed S, Kavalier A, Lyles JT, Kennelly EJ. 2010. White and green teas (Camellia sinensis var. sinensis): Variation in phenolic, methylxanthine, and antioxidant profiles. Journal of Food Science, 75(6): 541-548.

Van Hethof KH, Deboer HS, Wiseman SA, Lien N, Westrate JA, Tijburg LB. 1997. Consumption of green or black tea does not increase resistance of low-density lipoprotein to oxidation in humans. American Journal of Clinical Nutrition, 66(5): 1125-1132.

Yilmaz G, Kandemir N, Kinalioglu K. 2004. Effects of different pruning intervals on fresh shoot yield and some quality properties of tea (Camellia sinensis (L.) O. Kuntze) in Turkey. Pakistan Journal of Biyological Sciences, 7(7): 1208-1212. 